\title{
Capstone Design Project Course Pathways
}

Tom A. Eppes, University of Hartford, USA

Ivana Milanovic, University of Hartford, USA

\begin{abstract}
Capstones are open-ended undertakings where students are expected to creatively analyze, synthesize, and apply a wide-variety of learning outcomes from prior coursework. This paper discusses the structure, approach and evolution of the capstone project pathways within our College. Specifically two programs, MET and EET, have adopted different solutions towards the planning, organizing and execution. The areas of contrast among projects are: 1) sourcing, 2) type, 3) feedback and evaluation, 4) assessment methodology, 5) supplemental resources and 6) curricular strategy. For the first five, the advantages and disadvantages of different approaches are discussed along with the issues and benefits experienced by students, faculty and industry sponsors. In the sixth, a means to improve capstone readiness and performance is presented in which experiential courses within a topical area sequentially introduce challenging and openended assignments that foster cognitive learning.
\end{abstract}

Keywords: capstone readiness; open-ended design; scaffolding

\section{INTRODUCTION}

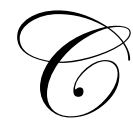

apstones are by nature integrating experiences and appear prominently in outcome assessment evaluation, thus for continued success, programs are highly reliant on graduating seniors demonstrating strong design skills. Efforts to improve capstone quality have been the subject of much work in recent years. The primary motivations behind these initiatives are: increasing industry relevance, showcasing graduate skills and the desire of faculty to adopt new best practices. However, it has been observed that too often students lack the necessary creativity, initiative and ability to develop robust solutions.

Recent surveys have identified a number of differences including topics covered, assessment, logistics, administration, faculty and industry involvement, project coordination, funding, and teaching beliefs/practices. Todd, Magleby, Sorensen, Swan, and Anthony (1995) targeted selected schools in North America with the aim to understand engineering practices in capstone education. A national study that focused on assessment was reported by McKenzie, Trevisan, Davis, and Beyerlein (2001). In a follow-up to Todd et al. (1995), Howe and Wilbarger (2006) gathered new snapshot on how capstone courses are organized. A survey specifically targeting faculty teaching load and funding levels was completed by Howe (2008). Complementing the previous work, Pembridge and Paretti (2010) examined teaching beliefs and practices.

Recommendations have been reported by a host of authors on how industry projects can be identified, selected and managed; some examples are Magleby, Todd, Pugh, and Sorensen (2001), Jordan and Schell (2002), Otieno and Mirman (2003), Myszka (2003), Farrel, Hesketh, Slater and Savelski (2004), and Blust and Myszka (2005). A perspective on the benefits and trade-offs of industry sponsorship for web-based projects was offered by Fry (2004). A holistic curricular strategy including an alternative laboratory structure that precedes the challenge of capstone design was reported by Milanovic and Eppes (2008) and Eppes, Milanovic, and Sweitzer (2011).

This paper discusses the recent history and experiences with capstone course design options in Mechanical Engineering Technology (MET) and Electronic Engineering Technology (EET). Each program has taken a strikingly different yet equally successful path in reaching the current practice. We compare and contrast the tradeoffs in which one approach may be more beneficial than another. The paper also identifies a strategy that incorporates multiple teaching and learning methods designed to better prepare students for the capstone experience. Significant improvements in capstone readiness are achieved across topical areas in which experiential courses sequentially introduce challenging and open-ended assignments. 


\section{COMPARING AND CONTRASTING CAPSTONES}

We begin by examining six points of contrast relative to capstones: 1) project sourcing, 2) type, 3) feedback and evaluation, 4) assessment methodology, 5) supplemental resources, and 6) curricular strategy. In both EET and MET, project sourcing is either industry-sponsored or developed internally by students in collaboration with faculty. Industry involvement is primarily associated with the MET program. Capstone instructors work directly with industry to identify appropriate projects. The process typically involves a visit of the sponsor to the campus, meeting with the faculty and a tour of facilities. At the meeting, the specific interests and capabilities of the sponsor and faculty are discussed. Subsequently, sponsors generate statements of work and identify representatives to serve as points of contact for the teams. Since the MET capstone is a single semester 3 credit course, it is important that the above preparations be completed so work can begin immediately. At the start of the semester, projects are assigned based on team interest, and a visit to the sponsoring company is arranged.

EET projects are mostly internally-sourced by the student teams. The EET curriculum consists of 2 successive capstone courses taken in the final year. The first course is built around a project proposal. Students work to identify an original and relevant design of their choosing integrating prior experiences into a project appropriate for the budgeted funds. Teams generate ideas and filter them down to a single proposal. The course culminates in a detailed design report that describes relevant objectives and outcomes. The second course is devoted mostly to implementation, troubleshooting and performance testing. This 2 course, 6 credit approach replaced a single 4 credit one and has resulted in higher quality projects and improved attainment of design objectives.

The second point of contrast is project type which may be design-based or test-oriented. The respective objectives are to: produce a working prototype and plan, test, analyze and interpret results. Within the MET program, both types of projects have been successfully undertaken. Capstones within the EET program are exclusively design-oriented, a long-standing custom due in part to the lack of industry-grade measurement equipment.

The third point of contrast is the feedback and evaluation method. In MET capstones, students deliver weekly oral presentations, time sheets and written reports that: 1) act as a catalyst for structure and organization, 2) report status, issues and next steps, 3) improve slide content and oral presentation skills, 4) strengthen team skills and 5) engender cross-project critique and sharing of ideas. In addition, industry sponsors are invited to attend these weekly review sessions. EET capstones require similar written reports; however, there are fewer and less robust oral presentations. Since the projects are internally-sourced, the participants in the weekly status reviews are the course instructor and teams.

The fourth point of comparison involves assessment methodology. MET capstones end with a symposium where teams deliver an oral presentation to an audience of faculty, students, and a panel of judges composed of practicing engineers drawn from local industry. Each judge completes two evaluation rubrics which rate the technical merit of the project and the professionalism of the presentation. The compiled data provide one measure of student outcome attainment and an external perspective of the results. The EET final capstone presentation is delivered to the instructor with other audience members being fellow students, faculty and invited guests from industry. Rubrics are completed by the instructor and supplemented with audience feedback in the area of oral presentation skills.

The fifth point of contrast involves supplemental resources, for example how out of pocket project costs are handled. In MET capstones, industry sponsors bear the full cost of raw materials/fixtures and serve as technical resources. In EET capstones, students pay for all electronic components not available from the Department's inventory. Historically, the students' cost share has ranged from less than $\$ 100$ to a maximum of $\$ 500$. In special cases, the Department has been willing to absorb the project costs. In both programs, all faculty members are available to act as technical resources.

The sixth area involves a curricular strategy that addresses the readiness of student entering the capstone. In conventional undergraduate ET curricula, design and research experiences are typically delayed until the capstone project. As a result, many students struggle with the creativity and initiative required to develop robust designs. 
There is also a strong pedagogical need to address the shortcomings that stem from the overuse of well-defined experiments. The MET program developed an embedded curricular multi-course solution using a scaffolded teaching methodology (Eppes, Milanovic, and Sweitzer, 2011).

Within each course, students are gradually introduced to challenging and open-ended assignments that foster cognitive learning. Higher-level skills important in the capstone course are strengthened: critical thinking, quantitative reasoning, teamwork, communication, information literacy, and design process. Set in a cooperative learning environment, teams encounter a series of assignments that build on existing skills while gradually expanding their knowledge and expertise. Assignments are organized into three sets of progressively challenging and scaffolded modules (Eppes, Milanovic, and Sweitzer, 2011). In this sense, scaffolding is linked to the learning theories of Vygotsky $(1962,1978)$ in which a learner's cognitive development is enabled by interaction with more capable members of the same culture - usually teachers or other students (Sticklen, Amey, Eskil, Hinds, and UrbanLurain, 2004). Having implemented this strategy for 3 years, the authors have found that students assume greater responsibility for their learning experiences and instructors are liberated to become mentors. Improved performance in the capstone has been noted as students enter better prepared for the rigors of unscripted design.

\section{BENEFITS \& TRADE-OFFS}

The course frameworks for both MET and EET capstones utilize established project management tools and techniques. A sequence of interim and final deliverables comprises the body of assessed student work. The due dates for these deliverables are distributed to equalize the documentation workload and avoid an 'end of the semester' crunch as shown in Table 1.

Table 1. Capstone Deliverables

\begin{tabular}{|c|c|c|c|}
\hline \multicolumn{2}{|c|}{ Deliverable } & Description & Due Date Within Course \\
\hline Proposal & EET & Goal and key design features of the prototype & Course 1, Week 1 \\
\hline $\begin{array}{l}\text { Statement of } \\
\text { Work }\end{array}$ & MET & $\begin{array}{l}\text { Description of the design or testing requirements and } \\
\text { deliverables }\end{array}$ & Week 2 \\
\hline \multirow[b]{2}{*}{$\begin{array}{l}\text { Weekly Progress } \\
\text { Reports }\end{array}$} & EET & Highlight of progress, issues and plan for resolution & \multirow[b]{2}{*}{ All Courses, Weeks 2-14 } \\
\hline & MET & $\begin{array}{l}\text { Same as above plus timesheet, PowerPoint slides } \\
\text { accompanied by presentation }\end{array}$ & \\
\hline System Design & EET & $\begin{array}{l}\text { - Functional block diagram } \\
\text { - Detailed design including component specs, and electrical } \\
\text { schematics } \\
\text { - List of components with part numbers and drawing } \\
\text { references } \\
\text { - Description of test and performance criteria }\end{array}$ & Course 1, Weeks 3-12 \\
\hline \multicolumn{4}{|c|}{ End-of-Semester Deliverables - All Courses } \\
\hline $\begin{array}{l}\text { Formal Oral } \\
\text { Presentation }\end{array}$ & MET & Team presentation to a panel of judges & Week 14 \\
\hline $\begin{array}{l}\text { Peer Team } \\
\text { Evaluations }\end{array}$ & MET & Self-assessment by team members & Week 14 \\
\hline \multirow{2}{*}{ Final Report } & MET & Comprehensive report in hard copy, DVD of slides & \multirow{2}{*}{ Week 14} \\
\hline & EET & Comprehensive report in hard copy & \\
\hline
\end{tabular}

MET industry sponsors provide a unique Statement of Work (SoW) that outlines the objectives, tasks and results required with the goal being to complete a functioning design or to execute a testing protocol. In response, teams develop detailed project plans and manage the work to completion. Based on faculty and instructor input as well as independent research, the teams craft a design proposal to build and test a working prototype. Both project sourcing approaches have advantages and disadvantages that must be addressed and managed to be successful. Table 2 provides a summary of these trade-offs. 
Table 2. Pros And Cons Of Industry-Sponsored Vs. Internally-Sourced

\begin{tabular}{|c|c|c|}
\hline \multirow{2}{*}{$\begin{array}{l}\text { Industry- } \\
\text { sponsored }\end{array}$} & Advantages & $\begin{array}{l}\text { Sponsors: } \\
\text { - Supply projects and provide resources } \\
\text { - Provide technical and management experience } \\
\text { - Create a stronger sense of responsibility } \\
\text { - Act as the voice of the customer } \\
\text { - Participate in final assessment }\end{array}$ \\
\hline & Disadvantages & $\begin{array}{l}\text { Having sponsors may: } \\
\text { - Require pre-planning before the capstone starts } \\
\text { - Impact the planned project schedule } \\
\text { - Change the SoW during the course of the project } \\
\text { - Increase coordination workload of instructor } \\
\text { - Increase the probability of failure }\end{array}$ \\
\hline \multirow{2}{*}{$\begin{array}{l}\text { Internally- } \\
\text { sourced }\end{array}$} & Advantages & $\begin{array}{l}\text { Students teams: } \\
\text { - Take ownership } \\
\text { - Create and manage project schedules with minimal outside influence }\end{array}$ \\
\hline & Disadvantages & $\begin{array}{l}\text { - Projects may not have real-world application } \\
\text { - Costs fall on teams and the Department }\end{array}$ \\
\hline
\end{tabular}

As discussed earlier, capstones may be either design-oriented or test-based. The former is exclusively used by EET while both are encountered in MET. Table 3 identifies the pros and cons of each. Some recent project abstracts for both MET and EET are provided below.

Table 3. Pros And Cons Of Design-Oriented Vs. Test-Based

\begin{tabular}{|l|c|l|}
\hline \multirow{2}{*}{$\begin{array}{l}\text { Design- } \\
\text { oriented }\end{array}$} & Advantages & - Strengthens design skills \\
\cline { 2 - 3 } & Disadvantages & - Instructor must ensure appropriate rigor \\
\hline \multirow{4}{*}{ Test-based } & Advantages & - Industry sponsors source projects \\
& & - Sponsor input and assistance throughout the project is available \\
\cline { 2 - 3 } & \multirow{2}{*}{ Disadvantages } & - Prototyping design skills not fostered \\
& - Access to measurement equipment and expertise may be problematic \\
\hline
\end{tabular}

Evaluation of Corrosion Preventative Compounds (MET) - The objective of this project is to examine the galvanic corrosion of propeller hubs exposed to an electrolyte. 36 aluminum panels were drilled with seven holes. A bolt and washer were inserted into each hole, and fastened with stainless steel fasteners at 15 in-lb torque. The fasteners have been treated with 14 different anti-corrosive compound coatings currently being used in industry. Each of the bracket panels have been either left bare, anodized or treated with chromate conversion to help simulate potential materials used to manufacture the hubs. After the bolts, washers, and nuts were fixed to the panels, they were set into the salt chamber for spraying. At the conclusion of the salt spraying periods, the panels were removed, disassembled and examined to document the corrosive behavior exhibited on the compound joints of the aluminum panels. The visual inspection was quantified using a five point scale provided by the sponsor and the results were used to inform customers why particular compound coatings are more suitable than others for certain types of products.

Diaphragm Pressurization Device (MET) - A Diaphragm Pressurization device to measure the burst pressure of a Nomex reinforced rubber diaphragm was designed, constructed, and tested for Hamilton Sundstrand's materials laboratory. The maximum design pressure of 1500 pounds per square inch (psi) was provided from compressed nitrogen. The device was required to test burst pressure of new diaphragms and compare to those with known real or simulated service histories. Proper material for the device and bolts used to hold it together were constructed to size to avoid failure at any point during its testing. Numerous calculations for material thickness and bolt size were developed. Compression of the diaphragm while in the pressure vessel was also a concern. The design required that the diaphragm not slip out before it burst, which would render the data invalid. After construction of 
the pressure vessel, several $3 / 4$ inch pieces of the diaphragm were placed inside of it and pressure was applied. This presentation will describe details of the design, considerations for the fabrication, and preliminary test results.

Low Power FM Transmitter (EET) - The objective of this project is to build, test, analyze and create a prototype of a low power frequency modulated (FM) transmitter. An FM transmitter is a portable device that plugs into a headphone jack or proprietary output port of a portable audio device such as a media player, guitar, compact disc $(C D)$ player or an IPod. The sound is then broadcast is mixed and sent out the transmitter at a frequency capable of being received by a commercial FM receiver. It will have a range of up to 30 feet (9 meters) and be compliant with Federal Communications Commission (FCC) regulations. It will be powered using a normal 9 volt battery. The circuit will consist of three stages. First, a pre-amp with a variable voltage gain up to 10 will accept the incoming audio signal. An oscillator will generate the radio frequency $(R F)$ carrier in the commercial FM band. Lastly, a mixer will combine the baseband audio with the RF signal produced by the oscillator and feed it to a small antenna.

Audio Summing Playback Device (EET) - The purpose of this project is to design and build an audio summing and playback device. This device will allow the user to play along with a pre-recorded audio track for practice or entertainment purposes. There is currently nothing like this on the market with the exception of large mixing consoles. The device will contain an input jack that will allow an instrument to be plugged in, e.g. electric guitar. A second jack will be an input for an external audio source, e.g. IPod or MP3 player. Separate volume controls will allow the user to combine the two signals in the desired proportion. The combined signal will be fed to an output capable of accepting a headphone connector so the user will be able to listen and play quietly. A switch to allow only the instrument input to be fed to the headphones will also be incorporated into the design. The device will be powered from a standard 115 volt, $60 \mathrm{~Hz}$ wall plug with an internal power supply.

Documentation and presentation deliverables are an important part of all capstones. They provide a valuable opportunity for students to actively learn and apply project management tools and techniques. These deliverables must be prepared in parallel to the core work of the project; however, the work must be evenly distributed over the semester. Written weekly status reports are required for all capstones in which teams describe progress since the last report, identify current and potential issues, propose solutions and plan for the future.

In addition to written weekly status reports, METs are tasked to deliver regular oral presentations (Richards and Milanovic, 2010). These practice sessions have been paying dividends for several years and have been endorsed by others as a result of similar experiences (Emanuel and Kerns, 2007). Verbal and written feedback is provided on a team and individual basis from the instructor, industry sponsor and a writing consultant. Slides are improved and new ones created, students sharpen their speaking skills and team synergy is strengthened. The content evolves over the course of the semester into that of the final presentation. Table 4 shows the pros and cons of the evaluation methods.

Table 4. Pros And Cons Of Feedback And Evaluation

\begin{tabular}{|c|c|c|}
\hline \multirow[t]{2}{*}{$\begin{array}{l}\text { Feedback \& } \\
\text { evaluation }\end{array}$} & Advantages & $\begin{array}{l}\text { Oral } \\
\text { - Improves team skills and clarifies roles and work to be done } \\
\text { - Strengthens presentation skills } \\
\text { - Enables final presentation slides to be refined and improved over several } \\
\text { iterations } \\
\text { Written } \\
\text { - Evenly distributes the documentation load } \\
\text { - Final report content is prepared ahead of time } \\
\text { - Students manage multiple tasks simultaneously } \\
\text { - Energy of the entire team is leveraged }\end{array}$ \\
\hline & Disadvantages & $\begin{array}{l}\text { Oral } \\
\text { - Requires slide and presentation effort every week } \\
\text { - May detract from design and testing activity } \\
\text { Written } \\
\text { - Burden of documentation adds to other project work } \\
\text { - Students are not familiar with many document requirements }\end{array}$ \\
\hline
\end{tabular}


All capstones use peer assessment administered at the end of the semester during the final presentation. MET capstones employ an external panel of judges, a natural extension of industry-sponsored projects. The quality of assessment and interaction between the panel and the teams during the final presentation is good since some judges have been indirectly involved in the projects. The peer and panel assessment data is both semantic (comments) and objective (numerical). The writing consultant provides input on the final grade to the instructor. EET capstones do not use judging panels; therefore assessment of student work rests solely with the instructor. Table 5 lists the pros and cons of the various assessment techniques.

Table 5. Pros And Cons Of Assessment Methodology

\begin{tabular}{|c|c|c|}
\hline \multirow{3}{*}{ Peer assessment } & & \\
\hline & Advantages & - Provides a better view of individual performance \\
\hline & Disadvantages & - Sometimes teams give high grades to all \\
\hline \multirow[t]{2}{*}{ Writing consultant } & Advantages & $\begin{array}{l}\text { - Strengthens organization of material and recursive editing of written and } \\
\text { oral content } \\
\text { - Provides a professional perspective to the final assessment process }\end{array}$ \\
\hline & Disadvantages & - External funds are needed to sustain the resource \\
\hline \multirow{2}{*}{$\begin{array}{l}\text { External judging } \\
\text { panel }\end{array}$} & Advantages & $\begin{array}{l}\text { - Provides an industry-based external perspective } \\
\text { - Creates a more formal setting which energizes teams }\end{array}$ \\
\hline & Disadvantages & $\begin{array}{l}\text { - Requires coordination and scheduling } \\
\text { - Easy to employ assessment tools are needed }\end{array}$ \\
\hline
\end{tabular}

Both capstones feature supplemental technical and monetary resources. The technical personnel that support MET capstones are comprised of the instructor, an industry sponsor, a writing consultant, as well as department faculty. Students must establish regular communication with the company representative in order to obtain additional project assistance, ensure customer satisfaction and adapt to possibly changing circumstances. Industry sponsors subsidize the cost of projects and may provide access to laboratory facilities, fabrication shops, equipment, raw materials and components. The writing consultant critiques interim document deliverables during the semester and participates in the assessment of the final report. Department faculty are available for technical assistance on request. EET capstones are overseen principally by the instructor with faculty serving as technical resources. EET students pay the cost of all outside purchased components and materials; however, in-stock devices are supplied. Table 6 shows the pros and cons of supplemental resources.

Table 6. Pros And Cons Of Supplemental Resources

\begin{tabular}{|l|l|l|}
\hline \multirow{4}{*}{$\begin{array}{l}\text { Supplemental } \\
\text { resources }\end{array}$} & $\begin{array}{l}\text { Technical } \\
\text { - Technical assistance improves overall project quality } \\
\text { - Burden of capstone course is shared across faculty } \\
\text { Monetary } \\
\text { - Budget can be capped and managed } \\
\text { - Funding is known before projects are formed }\end{array}$ \\
\cline { 2 - 4 } & Disadvantages & $\begin{array}{l}\text { Technical } \\
\text { - Program becomes dependent on external sources } \\
\text { Monetary } \\
\text { - Adds to program cost if absorbed by the institution }\end{array}$ \\
\hline
\end{tabular}

The curricular strategy described earlier strengthens capstone readiness and performance and represents a more holistic solution (Eppes et al., 2011). Results to date have yielded the following transformational benefits to students, instructors, experiential courses, and the curriculum: (1) students self-monitor, reflect and assume greater responsibility; (2) instructors move from being overseers to mentors; (3) liberal education and design process skills are strengthened and integrated; (4) knowledge across topical areas is synthesized; and (5) the quality and rigor of capstone performance improves. 


\section{CONCLUSION}

Our MET and EET programs have taken different avenues in the planning, organizing and execution of capstone projects. The areas of contrast within a project are: 1) sourcing, 2) type, 3) feedback and evaluation, 4) assessment methodology, 5) supplemental resources, and 6) curricular strategy. The approaches employed in the first five areas have advantages and disadvantages that necessitate trade-offs and careful management. In the sixth, a means to improve capstone readiness and performance is presented in which experiential courses within a topical area sequentially introduce challenging and open-ended assignments that foster cognitive learning.

Curricular design and capstone structure will continue to evolve with the most likely areas of focus being: 1) improve the curriculum prior to the capstone, 2) increase the use of external judging panels, 3) include more project management techniques, 4) increase emphasis on societal and ethical responsibilities, 5) use web-based collaboration tools to overcome time/distance, and 6) foster competition among teams.

\section{BIOGRAPHIES}

Tom A. Eppes is Associate Professor of Electrical and Computer Engineering at the University of Hartford. He earned a Ph.D. from the University of Michigan and an M.S. degree from Texas A\&M University. His research interests are fiber optic communications, photonics, laser manufacturing processes, multiphysics modeling, and remote laboratories.

Ivana Milanovic is Associate Professor of Mechanical Engineering at the University of Hartford. She earned a Ph.D. from Polytechnic University, New York, and an M.S. degree from the University of Belgrade. Her research interests are vortical flows, computational fluid dynamics, multiphysics modeling, and collaborative learning strategies.

\section{REFERENCES}

1. Blust, R. \& Myszka, D. (2005). Merging Design Competition and Industry Sponsored Projects, ASEE Annual Conference Proceedings, Portland, OR, Paper ASEE-2005-426.

2. Emanuel, J., \& Kerns, H. D. (2007). Industry Based Capstone Design Projects: You Can't Sell the Solution If You Can't Communicate, ASEE Annual Conference Proceedings, Hawaii, Paper ASEE-2007-2246.

3. Eppes, T. A., Milanovic, I., \& Sweitzer, F. (2011). Strengthening Capstone Skills in STEM Programs. Innovative Higher Education Journal, 37(1).

4. Farrel, S., Hesketh, R., Slater, C., \& Savelski, M. (2004). Industry and Academia: A Synergistic Interaction that Enhances Undergraduate Education. ASEE Annual Conference Proceedings, Salt Lake City, UT, Paper ASEE-2004-1517.

5. Fry, R. (2004). The Benefits and Trade-offs of Web-Based Industry Sponsored Projects. ASEE Annual Conference Proceedings, Salt Lake City, UT, Paper ASEE-2004-941.

6. Howe, S. \& Wilbarger, J. (2006). 2005 National Survey of Engineering Capstone Design Courses. ASEE Annual Conference Proceedings, Chicago, IL, Paper ASEE-2006-1781.

7. Howe, S. (2008). Focused Follow-Up to 2005 National Capstone Survey. ASEE Annual Conference Proceedings, Pittsburgh, PA, Paper ASEE-2008-2318.

8. Jordan, A., \& Schell, D. (2002). Design Projects and Industry Engagement in a Mechanical Engineering Technology Curriculum. ASEE Annual Conference Proceedings, Montreal, QE.

9. Magleby, S., Todd, R. H., Pugh, D. L., \& Sorensen, C. (2001). Selecting Appropriate Industrial Projects for Capstone Design Programs. International Journal of Engineering Education. 17(4-5), 400-405.

10. McKenzie, L. J., Trevisan, M. S., Davis, D. C., \& Beyerlein, S. W. (2004). Capstone Design Courses and Assessment: A National Study. ASEE Annual Conference Proceedings, Salt Lake City, UT.

11. Milanovic, I. M., \& Eppes, T. A. (2008). Modular, Adaptable, and Reusable Approach to Thermal-Fluids Outwitting the Norms (MARATHON). ASEE Annual Conference Proceedings, Pittsburgh, PA, Paper ASEE-2008-440.

12. Myszka, D. (2003). Capstone Projects that are Industry Sponsored, Interdisciplinary, and Include both Design and Build Tasks. ASEE Annual Conference Proceedings, Nashville, TN, Paper ASEE-2003-123. 
13. Otieno, A., \& Mirman, C. (2003). Engineering Technology Capstone Experience - An Industry Based Partnership. International Journal of Modern Engineering. 3(2).

14. Pembridge, J., \& Paretti, M. (2010). The Current State of Capstone Design Pedagogy. ASEE Annual Conference Proceedings, Louisville, KY, Paper ASEE-2010-811.

15. Richards, B., \& Milanovic, I. M. (2010). Partnership Between Engineering and Professional Writing. ASEE Annual Conference, Louisville, KY, Paper ASEE-2010-445.

16. Sticklen, J., Amey, M., Eskil, T., Hinds, T. \& Urban-Lurain, M., (2004). Application of Object-Centered Scaffolding to Introductory MatLab. ASEE Annual Conference Proceedings, Salt Lake City, UT.

17. Todd, R. H., Magleby, S. P., Sorensen, D. D., Swan, B. R., \& Anthony, D. K. (1995). A Survey of Capstone Engineering Courses in North America. Journal of Engineering Education. 84 (2), 165-174.

18. Vygotsky, L. S. (1962). Thought and Language. Cambridge, MA: MIT Press.

19. Vygotsky, L. S. (1978). Mind in Society. Cambridge, MA: Harvard University Press. 